\title{
Milk fatty acids as possible biomarkers to early diagnose elevated concentrations of blood plasma nonesterified fatty acids in dairy cows
}

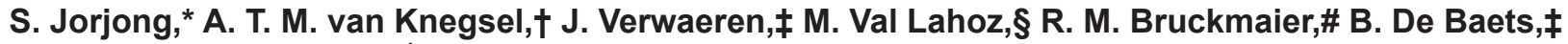 \\ B. Kemp,† and V. Fievez* \\ *Laboratory for Animal Nutrition and Animal Product Quality, Ghent University, Proefhoevestraat 10, 9090 Melle, Belgium \\ †Adaptation Physiology Group, Department of Animal Science, Wageningen University, PO Box 338, 6700 AH Wageningen, the Netherlands \\ ¥KERMIT, Department of Mathematical Modelling, Statistics and Bioinformatics, Ghent University, Coupure links 653, 9000 Ghent, Belgium \\ §Universitat Politècnica de València, Camino de Vera, 46022 Valencia, Spain \\ \#Veterinary Physiology, Vetsuisse Faculty, University of Bern, Bremgartenstrasse 109a, $\mathrm{CH}-3001$ Bern, Switzerland
}

\begin{abstract}
Most cows encounter a state of negative energy balance during the periparturient period, which may lead to metabolic disorders and impaired fertility. The aim of this study was to assess the potential of milk fatty acids as diagnostic tools of detrimental levels of blood plasma nonesterified fatty acids (NEFA), defined as NEFA concentrations beyond $0.6 \mathrm{mmol} / \mathrm{L}$, in a data set of 92 early lactating cows fed a glucogenic or lipogenic diet and subjected to 0-, 30-, or 60-d dry period before parturition. Milk was collected in wk 2, 3, 4, and 8 (n $=368$ ) and blood was sampled weekly from wk 2 to 8 after parturition. Milk was analyzed for milk fatty acids and blood plasma for NEFA. Data were classified as "at risk of detrimental blood plasma NEFA" (NEFA $\geq 0.6$ $\mathrm{mmol} / \mathrm{L}$ ) and "not at risk of detrimental blood plasma NEFA" (NEFA $<0.6 \mathrm{mmol} / \mathrm{L}$ ). Concentrations of 45 milk fatty acids and milk fat C18:1 cis-9-to-C15:0 ratio were subjected to a discriminant analysis. Milk fat C18:1 cis-9 revealed the most discriminating variable to identify detrimental blood plasma NEFA. A false positive rate of $10 \%$ allowed us to diagnose $46 \%$ of the detrimental blood plasma NEFA cases based on a milk fat C18:1 cis-9 concentration of at least $230 \mathrm{~g} / \mathrm{kg}$ of milk fatty acids. Additionally, it was assessed whether the milk fat C18:1 cis-9 concentrations of wk 2 could be used as an early warning for detrimental blood plasma NEFA risk during the first 8 wk in lactation. Cows with at least $240 \mathrm{~g} / \mathrm{kg}$ of C18:1 cis-9 in milk fat had about $50 \%$ chance to encounter blood plasma NEFA values of $0.6 \mathrm{mmol} / \mathrm{L}$ or more during the first $8 \mathrm{wk}$ of lactation, with a false positive rate of $11.4 \%$. Profit simulations were based on costs for cows suffering from detrimental blood plasma NEFA, and costs for preventive treatment based on daily dosing of propylene glycol
\end{abstract}

Received February 11, 2014.

Accepted August 5, 2014.

${ }^{1}$ Corresponding author: veerle.fievez@ugent.be for 3 wk. Given the relatively low incidence rate ( $8 \%$ of all observations), continuous monitoring of milk fatty acids during the first $8 \mathrm{wk}$ of lactation to diagnose detrimental blood plasma NEFA does not seem cost effective. On the contrary, milk fat C18:1 cis-9 of the second lactation week could be an early warning of cows at risk of detrimental blood NEFA. In this case, selective treatment may be cost effective.

Key words: milk fatty acid, nonesterified fatty acid, biomarker

\section{INTRODUCTION}

Most transition dairy cows are confronted with a negative energy balance (NEB) in early lactation caused by 3 primary reasons: increased energy demands at calving, decreased DMI shortly before and after calving, and lagging DMI compared with energy demand for milk production (Ospina et al., 2010a). Additionally, the supply of glucogenic precursors, in particular ruminal propionate which is largely converted into glucose in the liver, is often insufficient (Heuer et al., 2000). Accordingly, milk linear odd-chain FA (i.e., C15:0 and C17:0) might provide information on the cow's glucose status as they are de novo synthesized from propionyl-CoA by rumen bacteria or in the mammary gland (Vlaeminck et al., 2006).

Glucose insufficiency in the transition period further results in low blood glucose and insulin concentrations, inducing body fat mobilization and transportation of NEFA to several organs, among them reproductive tissues and the liver. In the liver, excessive supply of NEFA might result in metabolic disorders such as fatty liver and ketosis (Grummer, 1993), which particularly take place 2 to 7 wk after parturition. Additionally, elevated plasma NEFA concentrations increase the risk for displaced abomasum, clinical ketosis, metritis, and retained placenta (Ospina et al., 2010a). The critical NEFA concentration is about $0.3 \mathrm{mmol} / \mathrm{L}$ prepartum and $0.57 \mathrm{mmol} / \mathrm{L}$ postpartum (Ospina et al., 2010b), 
whereas a concentration of $1.0 \mathrm{mmol} / \mathrm{L}$ or more postcalving has been associated with increased culling rates in the first 2 mo of lactation (LeBlanc et al., 2005; Chapinal et al., 2011; Seifi et al., 2011). Furthermore, a high blood plasma NEFA concentration seems detrimental for dairy cow fertility (Garverick et al., 2013). This has been suggested to originate from deteriorated oocyte quality (Leroy et al., 2005).

Excessive amounts of NEFA, released during body fat mobilization, are also transferred to the milk. As these NEFA are particularly rich in long-chain FA, such as C18:1 cis-9 and C18:0 (Hostens et al., 2012), concentrations in milk fat of those FA might be linked to severity of NEB. Therefore, the objective of the current study was to assess whether milk FA are potential biomarkers for detrimental levels of blood plasma NEFA. For this objective, milk and blood plasma sampled during the first 8 wk after parturition were used. Samples were obtained from a large-scale experiment with 92 early lactating cows receiving either a glucogenic or a lipogenic diet in early lactation after a normal (60 d) or shortened $(30 \mathrm{~d})$ dry period or without dry period. The objective was approached in 4 steps: (1) measurement of FA in milk and NEFA in blood plasma; (2) discriminant analysis to determine the milk FA with the greatest biomarker potential; (3) assessment of the potential value of these milk FA as diagnostic and early warning biomarkers; and (4) economic validation.

\section{MATERIALS AND METHODS}

\section{Experimental Setup, Animals, and Housing}

The Institutional Animal Care and Use Committee of Wageningen University and Research Center approved the experimental protocol. Details about the experimental design have been reported earlier (van Knegsel et al., 2014). In short, Holstein-Friesian dairy cows (n $=108$ ) were selected from the Dairy Campus Research dairy herd (Wageningen University and Research Center Livestock Research, Lelystad, the Netherlands) for an experiment on the effect of dry period length (0, 30 , and $60 \mathrm{~d}$ ) and early lactation diet (glucogenic or lipogenic) on metabolic health (assessed through blood plasma BHBA, NEFA, glucose, IGF-1, and insulin). Cows were blocked for parity (primiparous or multiparous), expected calving date, milk production in the previous lactation, and BCS and randomly assigned to treatments $(0,30$, or $60 \mathrm{~d})$ and early lactation ration (glucogenic or lipogenic), resulting in a $3 \times 2$ experimental design. Cows were housed in a freestall with a slatted floor and cubicles. During lactation, cows were milked twice daily (0500 and $1630 \mathrm{~h}$ ). The drying-off protocol for cows with the 30- and 60-d dry period consisted of a transition to the far-off ration at $\mathrm{d} 7$ before drying off, and milking once daily at d 4 before drying off cows. At drying off, cows were treated with an intramammary antibiotic (Supermastidol, Virbac Animal Health, Barneveld, the Netherlands). Milk yield was recorded daily. From the original 108 cows in the experiment, 3 cows showed health problems postcalving and were not considered further. The health status of the cows was checked regularly by the animal care workers, but no further signs of health problems were observed in the 105 cows. Hence, from 105 cows of the experiment (17 or 18 in each of the 6 treatment groups), milk and blood samples were obtained. Blood samples were taken weekly from wk 3 precalving till wk 8 postcalving. Blood was sampled from the coccygeal vein into heparinized tubes. Blood plasma was obtained by centrifugation for $15 \mathrm{~min}$ at $3,000 \times g$ at $4^{\circ} \mathrm{C}$. Blood plasma samples were kept at $-20^{\circ} \mathrm{C}$ until analysis for plasma metabolites. Milk sampling for FA analysis took place every Friday morning in wk 2, 3, 4, and 8 postcalving. Milk samples were collected in $10-\mathrm{mL}$ tubes and were stored at $-20^{\circ} \mathrm{C}$. Frozen milk samples were sent to the Laboratory for Animal Nutrition and Animal Product Quality (Faculty of Bioscience Engineering, Ghent University, Belgium). From the 105 cows, 13 cows were excluded because the data were incomplete (missing milk FA of wk 2, 3, 4, and 8 or blood NEFA from wk 2 to 8 of lactation). Hence, only 92 of the 105 cows were used in data analysis.

Prepartum, dry cows received a dry cow ration, lactating cows received a lactating cow ration supporting $25 \mathrm{~kg}$ of milk. From 3 wk prepartum until 100 DIM, all cows were fed 1 of the experimental concentrates (lipogenic or glucogenic); lactating cows received $1 \mathrm{~kg} / \mathrm{d}$ of standard lactation concentrate in the milking parlor. Forage composition consisted prepartum of grass silage, corn silage, wheat straw, and a protein source (rapeseed meal or soybean meal) in a ratio of 39:25:25:11 (DM basis). Postpartum to 100 DIM, forage consisted of grass silage, corn silage, straw, and a protein source (rapeseed meal or soybean meal) in a ratio 51:34:2:13 (DM basis; Tables 1 and 2).

\section{Milk Analysis}

The FA profile was obtained after milk fat extraction (mini Röse-Gottlieb method, adapted from Chouinard et al., 1997), methylation (Stefanov et al., 2010), and gas chromatographic analysis of FAME (Agilent Technologies 7890A GC System equipped with a flame ionization detector, Agilent Technologies, Santa Clara, CA). Samples were injected by split injection (split ratio 1:50). The carrier gas was hydrogen, inlet pressure $246.38 \mathrm{kPa}$. Fatty acid peaks were identified based on 
Table 1. Ingredient and calculated ${ }^{1}$ chemical composition $(\mathrm{g} / \mathrm{kg}$ of $\mathrm{DM}$, unless otherwise noted) of glucogenic and lipogenic concentrate

\begin{tabular}{|c|c|c|}
\hline Item & Glucogenic & Lipogenic \\
\hline \multicolumn{3}{|l|}{ Ingredient (g/kg) } \\
\hline Rapeseed meal & 112.9 & 170.4 \\
\hline Corn & 530.8 & \\
\hline Palm kernel, expeller & & 212.6 \\
\hline Sugar beet pulp & 72.3 & 321.0 \\
\hline Wheat & 39.0 & 61.2 \\
\hline Soybean hulls & 4.9 & \\
\hline Soybean meal & 86.6 & 16.9 \\
\hline Soybean meal, formaldehyde treated & 22.4 & 18.4 \\
\hline Rapeseed meal, formaldehyde treated & 34.6 & 59.4 \\
\hline Energizer RP10 ${ }^{2}$ & & 20.1 \\
\hline Molasses & 57.0 & 47.0 \\
\hline Vinasses & & 39.2 \\
\hline Palm oil & 1.0 & 11.9 \\
\hline Calcium carbonate & 19.3 & 10.9 \\
\hline Magnesium oxide & 7.1 & 4.5 \\
\hline Sodium chloride & 7.5 & 5.1 \\
\hline Mineral-vitamin mixture ${ }^{3}$ & 2.3 & 2.4 \\
\hline \multicolumn{3}{|l|}{ Calculated chemical composition } \\
\hline $\mathrm{DM}$ (g/kg of product) & 873 & 879 \\
\hline $\mathrm{CP}$ & 181 & 194 \\
\hline Crude fat & 33 & 71 \\
\hline NDF & 178 & 379 \\
\hline $\mathrm{ADF}$ & 79 & 222 \\
\hline $\mathrm{ADL}$ & 18 & 50 \\
\hline Starch & 417 & 28 \\
\hline Sugars $^{4}$ & 77 & 103 \\
\hline Ash & 79 & 90 \\
\hline $\mathrm{DVE}^{5}$ & 120 & 120 \\
\hline $\mathrm{OEB}^{6}$ & 12 & 12 \\
\hline $\mathrm{NE}_{\mathrm{L}}^{7}(\mathrm{MJ} / \mathrm{kg}$ of $\mathrm{DM})$ & 7.7 & 7.7 \\
\hline
\end{tabular}

${ }^{1}$ Based on Centraal Veevoederbureau (CVB) table (CVB, 2005).

${ }^{2}$ Rumen-protected fat from palm oil (IFFCO International, Por Klang, Malaysia).

${ }^{3}$ Premix 2016 (Pre-Mervo UA Cooperation, Utrecht, the Netherlands).

${ }^{4}$ van Vuuren et al. (1993).

${ }^{5} \mathrm{DVE}=$ intestinal digestible protein (Tamminga et al., 1994).

${ }^{6} \mathrm{OEB}=$ degraded protein balance (Tamminga et al., 1994).

${ }^{7}$ Calculated with the Dutch net energy evaluation (VEM) system (Van Es, 1975).

their retention times. Separation of FAME was realized with a Supelco column (SP-2560, Sigma-Aldrich, Bellefonte, PA; $75 \mathrm{~m} \times 180 \mu \mathrm{m} \times 0.14 \mu \mathrm{m})$. The temperature program ran from a starting temperature of $70^{\circ} \mathrm{C}$ for 2 min, increasing $15^{\circ} \mathrm{C} / \mathrm{min}$ to $150^{\circ} \mathrm{C}$; from 150 to $165^{\circ} \mathrm{C}$ by an increase of $1^{\circ} \mathrm{C} / \mathrm{min}$, then $165^{\circ} \mathrm{C}$ was held for 12 min; from 165 to $170^{\circ} \mathrm{C}$ the temperature increased at $2^{\circ} \mathrm{C} / \mathrm{min}$, with $170^{\circ} \mathrm{C}$ held for $5 \mathrm{~min}$ and from 170 to $215^{\circ} \mathrm{C}$, an increase of $5^{\circ} \mathrm{C} / \mathrm{min}$ was applied, with the final temperature kept for 10 min. Fatty acid methyl esters were determined with Agilent ChemStation software (B.04.03; Agilent Technologies) and tridecanoic acid (C13:0; as triacylglyceride; Sigma, Bornem, Belgium) was used as internal standard. Fatty acids were expressed as grams per $100 \mathrm{~g}$ of FAME. Fatty acid peaks were identified through mixtures of methyl ester standards (BR2 and BR3, Larodan Fine Chemicals AB, Malmö, Sweden; Supelco 37, Supelco Analytical,
Bellefonte, PA; PUFA-3, Matreya LLC, Pleasant Gap, PA) based on retention times. Short-chain FA were corrected for their respective theoretical relative response factors (Ackman and Sipos, 1964; Wolff et al., 1995).

\section{Blood Plasma Metabolites}

Plasma metabolites were measured enzymatically with a selective analyzer (Cobas Mira 2, Hoffmann-La Roche, Basel, Switzerland) and by the use of commercial kits as described by van Dorland et al. (2009); NEFA was measured using commercial kit no. FA115 (Randox Laboratories Ltd., Ibach, Switzerland). The principle of the assay is as follows: NEFA, in the presence of ATP, CoA, and acetyl-CoA synthetase, forms acyl-CoA and the by-products AMP and pyrophosphate. Then, the product acyl-CoA is oxidized by acetyl-CoA oxidase, which produces hydrogen peroxide. Peroxidase acts on 
Table 2. Ingredient and calculated chemical composition ( $\mathrm{g} / \mathrm{kg}$ of DM, unless otherwise stated) of prepartum and postpartum rations ${ }^{1}$

\begin{tabular}{|c|c|c|c|c|}
\hline \multirow[b]{2}{*}{ Diet } & \multicolumn{2}{|c|}{ Prepartum ration } & \multicolumn{2}{|c|}{ Postpartum ration } \\
\hline & Dry & Lactating & Glucogenic & Lipogenic \\
\hline \multicolumn{5}{|l|}{ Ingredient } \\
\hline Grass silage & 391 & 484 & 338 & 338 \\
\hline Corn silage & 245 & 321 & 227 & 227 \\
\hline Soybean meal & 38 & 68 & 46 & 46 \\
\hline Rapeseed meal & 79 & 52 & 36 & 36 \\
\hline Rapeseed straw & 2 & 1 & 10 & 10 \\
\hline Wheat straw & 245 & 13 & 5 & 5 \\
\hline Concentrate & 0 & 56 & 338 & 338 \\
\hline \multicolumn{5}{|l|}{ Chemical composition } \\
\hline $\mathrm{DM}(\mathrm{g} / \mathrm{kg}$ of product) & 532 & 453 & 561 & 566 \\
\hline $\mathrm{CP}(\mathrm{g} / \mathrm{kg}$ of $\mathrm{DM})$ & 116 & 159 & 167 & 169 \\
\hline Crude fat & 26 & 31 & 31 & 37 \\
\hline NDF & 527 & 384 & 318 & 389 \\
\hline $\mathrm{ADF}$ & 326 & 229 & 182 & 224 \\
\hline Starch & 65 & 117 & 215 & 106 \\
\hline Sugars $^{2}$ & 67 & 80 & 82 & 85 \\
\hline Ash & 74 & 76 & 76 & 80 \\
\hline $\mathrm{DVE}^{3}$ & 47 & 80 & 87 & 84 \\
\hline $\mathrm{OEB}^{4}$ & 10 & 21 & 17 & 17 \\
\hline $\mathrm{NE}_{\mathrm{L}}^{5}(\mathrm{MJ} / \mathrm{kg}$ of $\mathrm{DM})$ & 5.26 & 6.48 & 6.55 & 6.52 \\
\hline \multicolumn{5}{|c|}{ FA composition ${ }^{6}(\mathrm{~g} / \mathrm{kg}$ of FAME) } \\
\hline $\mathrm{C} 12: 0$ & 0.83 & 5.26 & 0.53 & 40.0 \\
\hline C14:0 & 1.55 & 3.15 & 1.13 & 15.6 \\
\hline C16:0 & 136 & 164 & 133 & 370 \\
\hline C18:0 & 160 & 155 & 139 & 85.6 \\
\hline C18:1 cis-9 & 124 & 127 & 215 & 149 \\
\hline $\mathrm{C} 18: 2$ cis-9, cis-12 & 146 & 155 & 261 & 93.8 \\
\hline $\mathrm{C} 18: 3$ cis-9,cis-12,cis-15 & 397 & 354 & 248 & 169 \\
\hline
\end{tabular}

${ }^{1}$ Based on realized feed intake.

${ }^{2}$ van Vuuren et al. (1993).

${ }^{3} \mathrm{DVE}=$ intestinal digestible protein (Tamminga et al., 1994).

${ }^{4} \mathrm{OEB}=$ degraded protein balance (Tamminga et al., 1994).

${ }^{5}$ Calculated with the Dutch net energy evaluation (VEM) system (Van Es, 1975).

${ }^{6}$ Analysis of FA composition according to F. Gadeyne, G. V. Ranst, B. Vlaeminck, E. Vossen, P. Van der Meeren, and V. Fievez (all from Ghent University, Belgium, unpublished data).

the hydrogen peroxide in the presence of 3-methyl-Nethyl-N-( $\beta$-hydroxyethyl)-aniline and 4-aminoantipyrine to form the final reaction product that is a purple quinone.

\section{Statistical Analysis, Calculations, and Generation of Functions}

Descriptive Statistics. Milk fat C18:1 cis-9 concentration and blood plasma NEFA were subjected to repeated measures ANOVA (ANOVA mixed model of SAS; SAS Institute Inc., Cary, NC). Lactation week was considered as the repeated effect (wk 2 to 8 for blood plasma NEFA and wk 2, 3, 4, and 8 for milk fat C18:1 cis-9 concentration). Cow was defined as random effect. Dry period length $(0,30$, or 60 d), diet (glucogenic or lipogenic), week (2 to 8 ), and the relevant interaction terms were included in the model as fixed effects. A first-order autoregressive structure $[\mathrm{AR}(1)]$ was the best fit and was used to account for within-dry period by diet variation of NEFA, whereas a first-order heterogeneous structure was used to account for withindry period by diet variation of milk fat C18:1 cis-9 concentration.

NEFA Threshold Definition. The NEFA threshold in postpartum blood plasma samples was set at 0.6 mmol/L (Ospina et al., 2010a), where NEFA values greater than or equal to $0.6 \mathrm{mmol} / \mathrm{L}$ were classified as 1 , which stands for "at risk of detrimental blood plasma NEFA"; NEFA values lower than $0.6 \mathrm{mmol} / \mathrm{L}$ were classified as 0 , which stands for "not at risk of detrimental blood plasma NEFA."

Discriminant Function. The aim of this function is to maximize the distance between the categories (i.e., to come up with an equation that has a strong discriminatory power between groups). The 45 milk FA, as well as the milk fat C18:1 cis-9-to-C15:0 ratio, were subjected to a discriminant analysis performed by SPSS 
21.0 (SPSS Inc., Chicago, IL). Discriminant analysis was used to identify the most discriminating milk FA for classification based on blood plasma NEFA concentration. Given the large variation in range of milk FA, standardized canonical discriminant coefficients were used to compare variables. Greater absolute values of these coefficients correspond to variables with greater discriminating ability. After this first exploratory linear discriminant analysis, which aimed to identify the most discriminating milk FA, a second linear discriminant analysis was run in which classification was based on the most discriminating milk FA. The performance of both classification models (either based on all milk FA or on a single milk FA) were assessed through crossvalidated discriminant analysis (default leave-one-out procedure in SPSS 21.0).

Empirical Cumulative Probability Distributions for Diagnosis of Detrimental Blood NEFA. Empirical cumulative probability distributions were generated expressing the cumulative probability of milk fat C18:1 cis-9 concentration. In particular, the cumulative probability distribution of milk fat C18:1 cis-9 concentration in case of elevated and low blood plasma NEFA (detrimental blood plasma NEFA cows) were considered and denoted $g 1$ and $g 2$, respectively. Denoting the milk fat oleic acid (C18:1 cis-9) concentration as $O$ (the random variable under study), the corresponding curves were constructed through a stepwise increase of the milk fat C18:1 cis-9 concentration $o$ from the minimum to the maximum value observed in the study:

$g 1(o)=($ Number of cases with elevated blood plasma

NEFA for which $O \leq o$ )/(Total number of cases

with elevated blood plasma NEFA in the study), and

$g \mathscr{2}(o)=($ Number of cases with low blood plasma

NEFA for which $O \leq o$ )/(Total number of cases with low blood plasma NEFA in the study).

Empirical Cumulative Probability Distributions for Early Warning of Detrimental Blood Plasma NEFA. In our study, early warning potential for detrimental blood plasma NEFA was assessed. For this purpose, milk fat C18:1 cis-9 was determined in wk 2 after parturition, whereas cows were classified based on detrimental blood plasma NEFA from wk 2 to 8 . For this classification, cows were considered at risk of detrimental blood plasma NEFA in early lactation when the maximum blood plasma NEFA concentration at any time in this 7 -wk period was greater than $0.6 \mathrm{mmol} / \mathrm{L}$.
Empirical probability distributions were generated as described previously (diagnosis), but now including milk FA data of wk 2 only and the 0 or 1 classification based on the maximum blood plasma NEFA concentration observed in wk 2 till 8 of lactation. The following cumulative probability distributions for use in early warning were considered: the cumulative probability distribution of the milk fat C18:1 cis-9 concentration in wk 2 of lactation in cases of elevated and low blood plasma NEFA in the first 8 wk in lactation, denoted $e 1$ and $e \mathcal{2}$, respectively. Denoting the milk fat oleic acid (C18:1 cis-9) concentration in wk 2 as $O_{2}$ (the random variable under study), the corresponding curves were constructed through a stepwise increase of the milk fat C18:1 cis-9 concentration $o$ from the minimum to the maximum value observed in the study:

$e 1(o)=$ (Number of elevated-blood plasma NEFA cows in the first 8 wk in lactation for which $O_{2} \leq o$ )/

(Total number of cows with elevated blood plasma

NEFA in first 8 wk in lactation), and

e2(o) $=$ (Number of low-blood plasma NEFA cows

in the first 8 wk in lactation for which $\mathrm{O}_{2} \leq o$ )/

(Total number of cows with low blood plasma

NEFA in first $8 \mathrm{wk}$ in lactation).

Logistic Curve Fitting. Further, a logistic curve was fitted to the empirical cumulative probability distributions. This curve is described based on the slope $\left(\beta_{0}\right)$, the inflection point of the curve $\left(\beta_{1}\right)$, and the upper limit $\left(\beta_{2}\right)$, which here equals 1 :

$$
y=\frac{\beta_{2}}{1+\exp \left[-\beta_{0} \times\left(x-\beta_{1}\right)\right]} .
$$

Economic Cost Function for Prevention of Detrimental Blood Plasma NEFA. The expected economic cost of detrimental blood plasma NEFA was calculated based on following cost parameters and probabilities:

$a=$ Financial loss of an ill cow $(€)$ due to a decrease in reproductive performance of detrimental blood plasma NEFA cows. Costs were estimated at $€ 25$ per case (Geishauser et al., 2001). For the current simulation, costs of $€ 15,25$, and 35 were considered.

$b=$ Financial cost of pre-emptive treatment $(€)$ based on the use of propylene glycol (PEG), which 
is reported to allow effective treatment or prevention of elevated blood plasma NEFA development with application rates varying between 200 and 500 g/d during 3 wk (Johnson, 1954; Grummer et al., 1994; Formigoni et al., 1996; Miyoshi et al., 2001) and costs for PEG of $€ 1.1 / \mathrm{kg}$.

Labor costs (e.g., for pre-emptive PEG treatment or for cow separation for veterinary inspection) were not included in the current cost estimations.

$I=$ The event a cow suffers from elevated blood plasma NEFA.

$R=$ Milk fat C18:1 cis-9 concentration for that cow.

A threshold $(\theta)$ was selected and it was assumed to preemptively treat a cow when $R>\theta$. Hence, the probability $\mathrm{P}(I)$ for a cow to be ill is then given by

$$
\begin{gathered}
\mathrm{P}(I)=\mathrm{P}(I / R \leq \theta) \times \mathrm{P}(R \leq \theta) \\
+\mathrm{P}(I / R>\theta) \times \mathrm{P}(R>\theta) .
\end{gathered}
$$

If the treatment is fully effective to treat detrimental blood plasma NEFA, then $\mathrm{P}(I / R>\theta)=0$ and $\mathrm{P}(I)$ reduces to

$$
\mathrm{P}(I)=\mathrm{P}(I / R \leq \theta) \times \mathrm{P}(R \leq \theta) .
$$

In those equations, the probability for a random cow to have milk fat $\mathrm{C} 18: 1$ cis-9 less than $\theta, \mathrm{P}(R \leq \theta)$ was assessed as the concentration of the number of observations with $R \leq \theta$ to the total number of observations in the study. Similarly, $\mathrm{P}(R>\theta)$ was assessed as the concentration of the number of cows that have $R>\theta$ to the total number of cows.

Under this scenario, a cost function $\mathrm{C}(\theta)$ is built, including $1 /$ (financial loss of a detrimental blood plasma cow when not treated), that is, all detrimental blood plasma cows with $R \leq \theta$; and 2 /(financial cost of the pre-emptive treatment), that is, all cows with $R>\theta$. Hence, the expected economic cost $(\mathrm{C})$ of a cow is

$$
\begin{gathered}
\mathrm{C}(\theta)=\mathrm{P}(I) \times a+\mathrm{P}(R>\theta) \times b=\mathrm{P}(I / R \leq \theta) \\
\times \mathrm{P}(R \leq \theta) \times a+\mathrm{P}(R>\theta) \times b .
\end{gathered}
$$

\section{RESULTS}

\section{Classification Based on Blood Plasma NEFA Thresholds and Influence of Experimental Factors (Dietary and Dry Period Management)}

Of all 368 observations in wk 2, 3, 4, and 8 after parturition, $8 \%$ of the cases blood plasma NEFA were greater than $0.6 \mathrm{mmol} / \mathrm{L}$. However, in the case of early warning $(\mathrm{n}=92), 24 \%$ of the animals were classified at risk to develop detrimental blood plasma NEFA concentration during the first $8 \mathrm{wk}$ in lactation.

Blood plasma NEFA concentrations were greater in early lactation $(P<0.001)$, and blood plasma NEFA was affected by dry period management $(P<0.001)$, but differences became smaller when lactation progressed (dry period management by week interaction; $P=0.0056$; Figure 1a). Particularly, omission of the dry period resulted in a lower blood plasma NEFA concentration $(P<0.001$; Figure 1a). Blood plasma NEFA was also affected by diet, with the glucogenic diet suppressing its concentration $(0.20$ vs. $0.25 \mathrm{mmol} / \mathrm{L}$ for the glucogenic and lipogenic diet, respectively; $P=0.0219$ ).

\section{Identification of Milk FA Predominantly Linked with Blood NEFA Concentrations: Discriminant Analysis and Correlations}

Of the 45 milk FA and $\mathrm{C} 18: 1$ cis-9-to-C15:0 ratio used to perform the discriminant analysis, milk fat C18:1 cis-9 revealed the most discriminating variable for the classification of detrimental blood plasma NEFA cases. Identification of the most discriminating variable was based on the standardized canonical discriminant function coefficients. The second retained variable was C16:0. Cross-validation results for grouping based on all variables resulted in an overall classification accuracy of $79.9 \%$. More specifically, 80.3 and $75.0 \%$ of the cases of the blood plasma NEFA groups 0 (specificity) and 1 (sensitivity) were classified correctly, respectively. Cross-validation based on the most discriminating milk FA only (i.e., C18:1 cis-9) showed overall classification accuracy of $78.8 \%$, specificity of $79.1 \%$, and sensitivity of $75.0 \%$. Hence, classification based on C18:1 cis-9 was only slightly less specific as compared with classification based on the full parameter set, whereas sensitivity was maintained. Accordingly, the potential of this single milk FA was further emphasized in the current paper.

In accordance with blood NEFA concentrations, milk fat C18:1 cis-9 concentration decreased with week in lactation $(P<0.001)$ and was lower for cows without or with a short dry period $(P<0.001)$, with differences becoming smaller and disappearing when the lactation progressed (dry period management by week interaction; $P<0.001$; Figure 1b). Milk fat C18:1 cis-9 concentration was not affected by diet $(P=0.635)$. Further detailed information on the milk FA composition, in relation to the dry period length and glucogenic versus lipogenic ration has been reported by van Knegsel et al. (2014). The relation between milk fat C18:1 cis-9 concentration and blood NEFA is further confirmed through the positive relation between both 


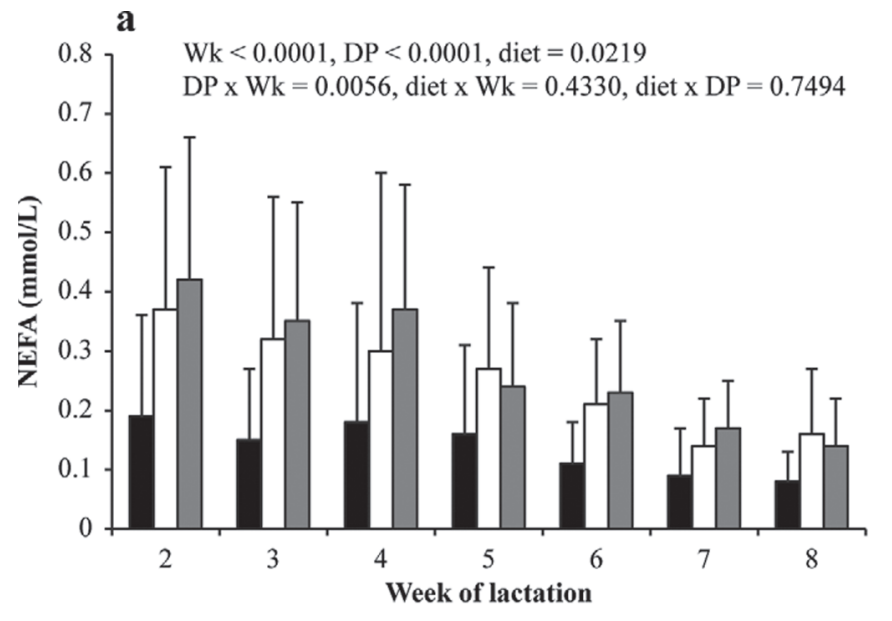

b

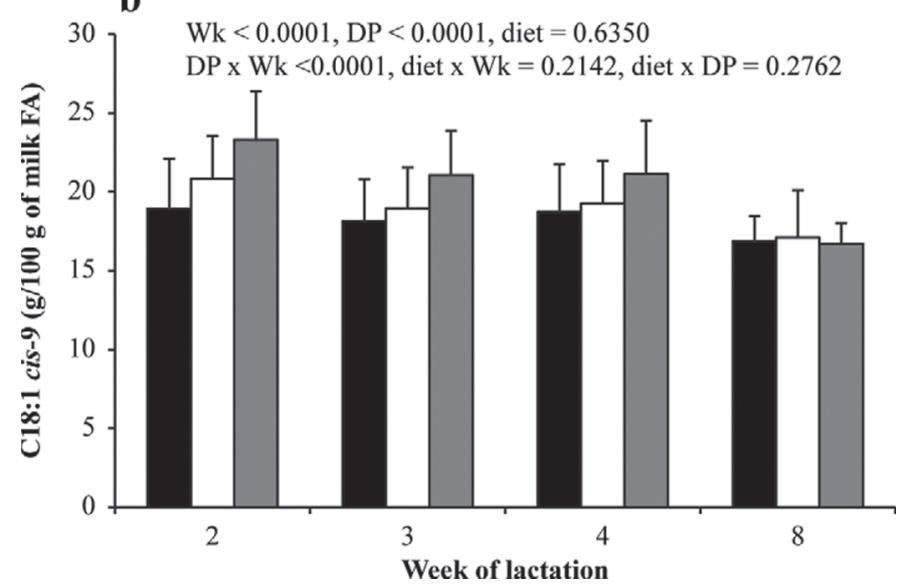

Figure 1. Blood plasma NEFA concentration (a) and milk fat C18:1 cis-9 concentration (b) of dairy cows fed a glucogenic or lipogenic diet (diet) with dry period (DP) length of 0 (black bar), 30 (white bar), or $60 \mathrm{~d}$ (gray bar) during wk 2, 3, 4, and 8 of lactation $(\mathrm{Wk})$. Values represent means per week, error bars present standard deviations. $P$-values show main effects and interaction effects.

metabolites (Figure 2), despite a relatively modest $R^{2}$ value, indicating limited potential for direct prediction of the blood NEFA concentration from the milk fat C18:1 cis-9 concentration.

\section{Empirical Cumulative Probability Distributions for Diagnosis of Detrimental Blood NEFA}

Logistic curves were fitted presenting both the proportion of animals at risk and not at risk of detrimental blood plasma NEFA in relation to the milk fat C18:1 cis-9 concentration (ranging from 12.5 to $30.6 \mathrm{~g} / 100$ $\mathrm{g}$ of milk FA). The $\beta_{1}$ value for the logistic curve of animals with detrimental blood plasma NEFA equaled 23.6 , which indicates that $50 \%$ of all observations having a blood plasma NEFA concentration of $0.6 \mathrm{mmol} / \mathrm{L}$ or more were associated with a milk fat $\mathrm{C} 18: 1$ cis-9 concentration equal to or greater than $\beta_{1}$ (Figure 3a). This situation was associated with only $6.5 \%$ false positives (i.e., animals showing milk fat $\mathrm{C} 18: 1$ cis-9 values of at least $24 \mathrm{~g} / 100 \mathrm{~g}$ of milk FA, but with blood plasma NEFA $<0.6 \mathrm{mmol} / \mathrm{L})$.

\section{Empirical Cumulative Probability Distributions for Early Warning of Detrimental Blood Plasma NEFA}

About half of the cows $(45 \%, \mathrm{n}=10)$ showing detrimental blood plasma NEFA during the first $8 \mathrm{wk}$ in lactation showed a milk fat $\mathrm{C} 18: 1$ cis-9 concentration of $24 \mathrm{~g} / 100 \mathrm{~g}$ of milk FA or more in wk 2, with a false positive rate of $11.4 \%$. When the milk fat $\mathrm{C} 18: 1$ cis-9 concentration was below $20 \mathrm{~g} / 100 \mathrm{~g}$ of milk FA, the risk of encountering detrimental blood plasma NEFA was less than 15\% (Figure 3b).

\section{Economic Cost Function}

Figures $4 \mathrm{a}$ and $4 \mathrm{~b}$ present the costs associated with selective PEG treatment based on the milk fat C18:1 cis-9 concentration. Simulations were performed assuming costs associated with elevated blood plasma NEFA could vary between $€ 15$ and 35 per case, and costs for 3 wk of daily PEG supplementation varying from 200 to $500 \mathrm{~g} / \mathrm{d}$ equaled $€ 4.6$ to 11.6 per case. The $\mathrm{x}$-axis represents increasing thresholds $(\theta)$ and simulations were based on selective treatment of animals when $R$ $>\theta$. Thresholds varied from 1 unit below the minimum (S1) to 1 unit above the maximum (S2) observation in the current study. Accordingly, S2 (extreme right on the $\mathrm{x}$-axis) represents a situation where none of the animals are treated, whereas S1 (extreme left on the $\mathrm{x}$-axis) represents a situation where all of the animals are treated. When costs reach a local minimum, it is of economic interest to selectively treat animals. Figure 4a represents costs associated with selective treatment when diagnosing elevated blood plasma NEFA. Based on the current data set, weekly monitoring of milk fat C18:1 cis-9 to selectively treat animals is of no economic interest in general (maximum benefit of less than $€ 0.5 /$ case for the situation with the combination of the lowest amount of PEG and the highest cost of €35; Figure 4a). No treatment is most often associated with the greatest economic return.

Finally, Figure 4b represents costs associated with selective treatment of animals based on monitoring of milk fat C18:1 cis-9 in wk 2 after parturition (early warning). In this case, PEG treatment is assumed to prevent blood NEFA concentration to rise to detrimental levels afterward. The maximum economic benefit is associated with a selective treatment of animals show- 


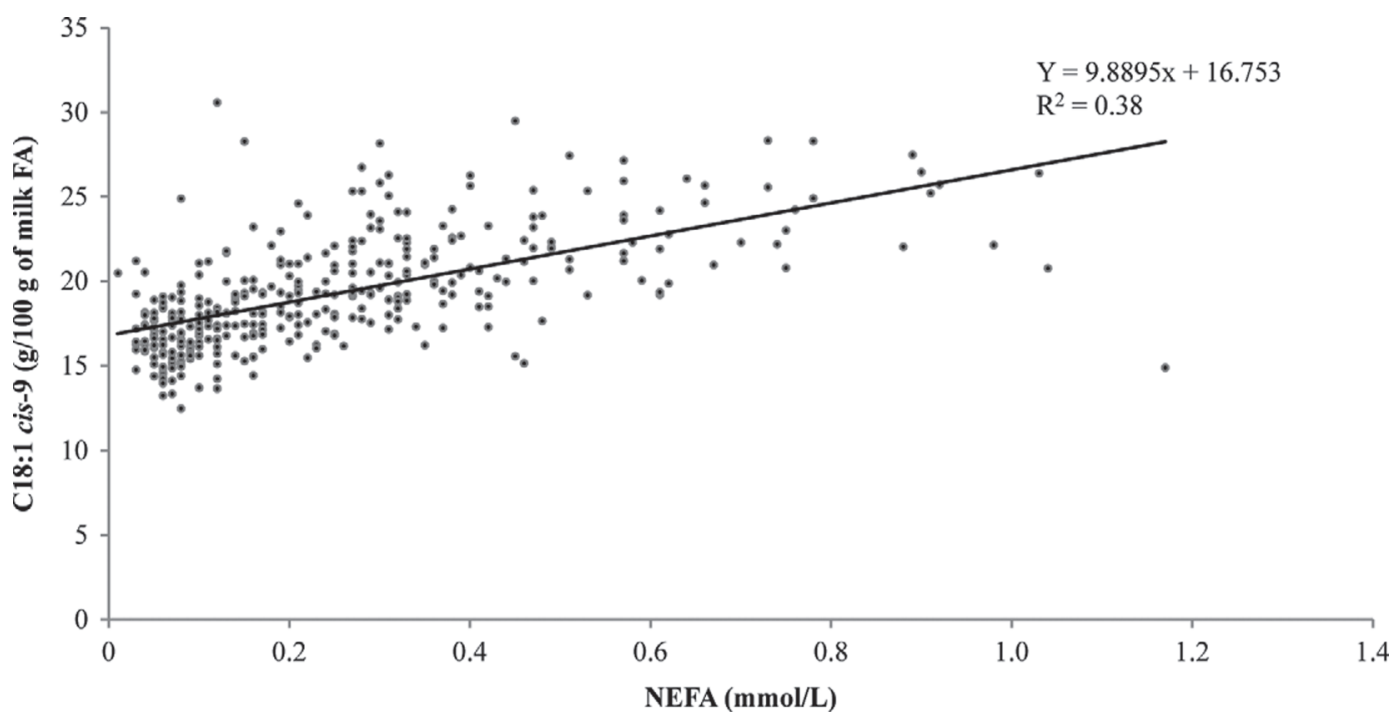

Figure 2. Correlation between blood plasma NEFA and milk fat C18:1 cis-9 concentrations of wk 2, 3, 4, and 8 in lactation (n $=368 ; \mathrm{R}^{2}$ $=0.38$ )

ing milk fat $\mathrm{C} 18: 1$ cis-9 concentration of $23 \mathrm{~g} / 100 \mathrm{~g}$ of milk FA or more. In this case, economic benefits are limited to $€ 2$ per cow.

\section{DISCUSSION}

\section{Blood Plasma NEFA Threshold Value}

Serum NEFA concentrations typically increase around parturition (0.4 to $1.2 \mathrm{mmol} / \mathrm{L}$; Leroy et al., 2005) and are a major characteristic of the NEB early postpartum. Moreover, elevated blood serum NEFA particularly tend to negatively affect reproductive performance and oocyte development (Leroy et al., 2005). Elevated blood serum NEFA concentrations were further linked to increased incidence of displaced abomasum (Cameron et al., 1998), clinical ketosis, metritis, or retained placenta, with critical postpartum blood serum NEFA concentrations varying from 0.57 (Ospina et al., 2010a) to 0.72 (Ospina et al., 2010b) and $0.8 \mathrm{mmol} / \mathrm{L}$ (Roberts et al., 2012). A threshold of $0.6 \mathrm{mmol} / \mathrm{L}$ for blood plasma NEFA concentration was used in the current study.

\section{Milk FA as an Indicator of Elevated Blood Plasma NEFA}

During a period of NEB, NEFA in plasma are increased. The major NEFA released are C16:0, C18:0, and C18:1 cis-9 (Hostens et al., 2012), with a further possible conversion of $\mathrm{C} 18: 0$ to $\mathrm{C} 18: 1$ cis-9 in the mammary gland through the action of $\Delta 9$-desaturase (Leroy et al., 2005). This explains the positive relation in the current study between milk fat C18:1 cis-9 con- centrations and blood plasma NEFA concentrations. Accordingly, milk fat C18:1 cis-9 was identified to be useful for diagnosis and early warning of cows suffering from a severe NEB. However, the positive correlation between blood NEFA concentrations and milk C18:1 cis-9 is only modest $\left(\mathrm{R}^{2}=0.383\right)$, indicating that a direct prediction of blood NEFA concentrations from milk C18:1 cis-9 concentrations is not accurate (Figure 2). Moreover, the thresholds, established here, have only been validated for the current diets and management and further validation under different conditions is required.

\section{Potential of Milk Fat Characteristics as Biomarkers for Elevated Blood Plasma NEFA as Compared with Other Cow-Side Tests}

Currently, on-farm NEFA tests in blood are readily available (i.e., NEFA-C kit, Wako Chemicals USA Inc., Richmond, VA). However, blood tests are laborious and invasive. Moreover, the available cow-side blood NEFA test shows additional drawbacks (e.g., requirement of a large number of samples to justify the equipment costs and expert training). Hence, this kit is not well adaptable for on farm use. This usually impedes testing capabilities to very large farms or veterinary clinics (Townsend, 2011). In our study, logistic curves indicated that $64.3 \%$ of the animals at risk of detrimental blood NEFA showed milk fat C18:1 cis-9 concentrations of $24 \mathrm{~g} / 100 \mathrm{~g}$ of milk FA or higher, with a specificity of $84.4 \%$. Interestingly, the cross-validated discriminant analysis showed a specificity value of $79.1 \%$ and sensitivity of $75 \%$, with an overall correct classification rate of $78.8 \%$. 


\section{Cost Effectiveness of Selective Treatment Based on Biomarker Monitoring}

Cow-side tests will only be used routinely to allow selective treatment of cows at risk when the price of such tests does not exceed potential gain. Hence, cost functions were constructed based on economic losses for detrimental blood NEFA, between $€ 15$ and 35/cow (Geishauser et al., 2001). In the current study it was assumed that elevated blood plasma NEFA could be pre-emptively treated with PEG (200 to $500 \mathrm{~g} / \mathrm{d}$ during $3 \mathrm{wk}$ ) of which costs were assumed to be $€ 1.1 / \mathrm{kg}$. Propylene glycol is a glucogenic precursor that has been used since the 1950s and is still used today for both treatment and prevention of ketosis before and after parturition. It effectively seems to increase milk production, prevent ketosis, improve reproduction, increase blood glucose, and decrease blood NEFA (Nielsen and Ingvartsen, 2004; Lomander et al., 2012). The economic benefit strongly depends on the incidence rate. When a large proportion of animals encounter the metabolic problem, the most cost effective solution might be to treat all animals, whereas the opposite is true when the incidence rate is low. This is illustrated when considering all NEFA observations (diagnosis; $\mathrm{n}=368$; Figure 4 a): only $8 \%$ of the observations in wk $2,3,4$, and 8 , blood plasma NEFA were greater than $0.6 \mathrm{mmol} / \mathrm{L}$. Hence, in this case, monitoring milk FA to diagnose and selectively treat animals with elevated blood plasma NEFA did not return any economic benefit (Figure 4a). However, in the case of early warning $(\mathrm{n}=92), 24 \%$ of the animals were classified as at risk to develop a detrimental blood plasma NEFA during the first $8 \mathrm{wk}$ in lactation (Figure $4 \mathrm{~b}$ ).

Based on the current cost effectiveness simulation, a maximum gain of about $€ 2$ per case was calculated for early warning of detrimental blood plasma NEFA. Obviously, costs for milk FA analysis have to be put in this perspective. Hence, milk fat C18:1 cis-9 seems promising as an early indicator of detrimental blood plasma NEFA, as it might be routinely analyzed through Fourier transform infrared spectrometry (Soyeurt et al., 2006; Rutten et al., 2009). A single analysis at a specific moment early after parturition (in the current case, 2 wk after calving) seems of interest in this respect as selective treatment of animals showing a milk fat C18:1 cis-9 concentration of $23 \mathrm{~g} / 100 \mathrm{~g}$ of milk FA or more might suffice (Figure $4 \mathrm{~b}$ ).

\section{CONCLUSIONS}

Milk fat C18:1 cis-9 shows potential as an early warning biomarker for compromised metabolic status in dairy cows during the first 2 mo of lactation. Under

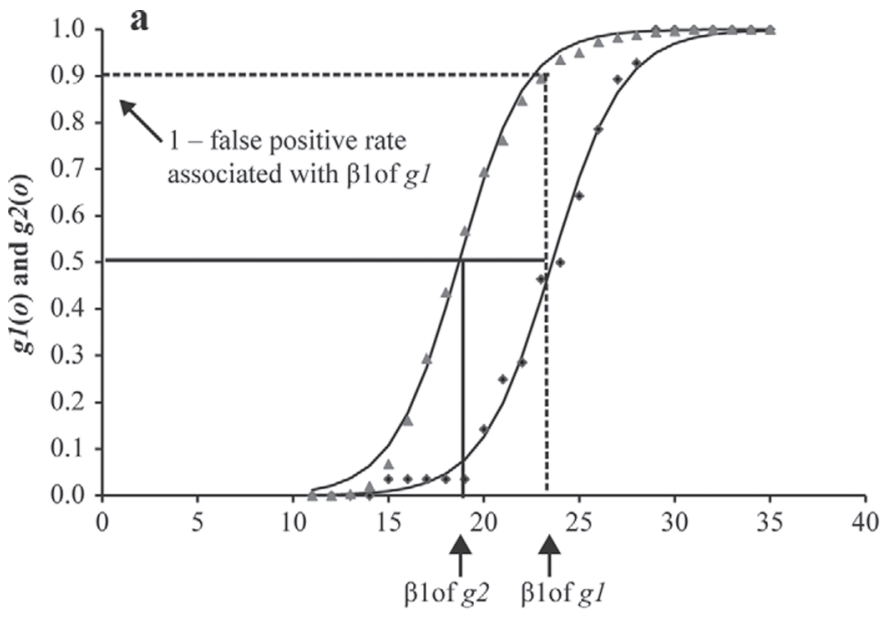

Milk fat C18:1 cis-9 (g/100 g of milk FA)

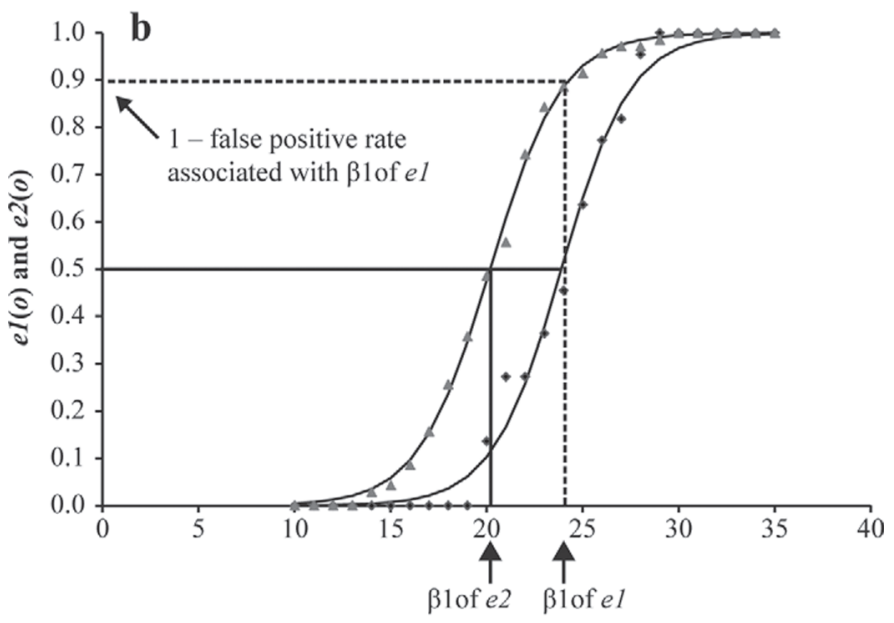

Milk fat C18:1 cis-9 (g/100 g of milk FA)

Figure 3. (a) A logistic curve, $g 1$, representing the cumulative probability distribution of milk fat $\mathrm{C} 18: 1$ cis-9 concentration, $(O) \leq o$, in case of elevated blood plasma NEFA (NEFA $\geq 0.6 \mathrm{mmol} / \mathrm{L}$; black diamonds) to the total number of cases showing detrimental blood plasma NEFA. The logistic curve is characterized by its slope $\left(\beta_{0}=\right.$ $0.54)$ and inflection point $\left(\beta_{1}=23.6\right)$. Similarly, cases having nondetrimental blood plasma NEFA proportionally to the total number of cases with nondetrimental blood plasma NEFA (g2) in relation to $O$ $\leq o$ (gray triangles) were presented, with $\beta_{0}$ and $\beta_{1}$ of 0.57 and 18.7, respectively. (b) A logistic curve, $e 1$, representing the cumulative probability distribution of milk fat C18:1 cis-9 concentration of wk 2 in lactation $\left(\mathrm{O}_{2}\right) \leq o$ with detrimental blood plasma NEFA $(\geq 0.6 \mathrm{mmol} / \mathrm{L}$; black diamonds) at any time between wh 2 and 8 in lactation relative to the total number of observations with detrimental blood plasma NEFA. The logistic curve is characterized by its slope $\left(\beta_{0}=0.56\right)$ and inflection point $\left(\beta_{1}=23.9\right)$. Similarly, cows having nondetrimental blood plasma NEFA (gray triangles) during the first $8 \mathrm{wk}$ in lactation proportionally to the total number of cows with nondetrimental blood plasma NEFA in relation to $O_{2} \leq o$ were presented (e2), with $\beta_{0}$ and $\beta_{1}$ of 0.54 and 20.2 , respectively.

the current feeding and management conditions, a milk fat C18:1 cis-9 concentration of $24 \mathrm{~g} / 100 \mathrm{~g}$ of milk FA or more, measured in the second week of lactation, could be used as an early warning for elevated blood plasma NEFA $(\geq 0.6 \mathrm{mmol} / \mathrm{L})$. 

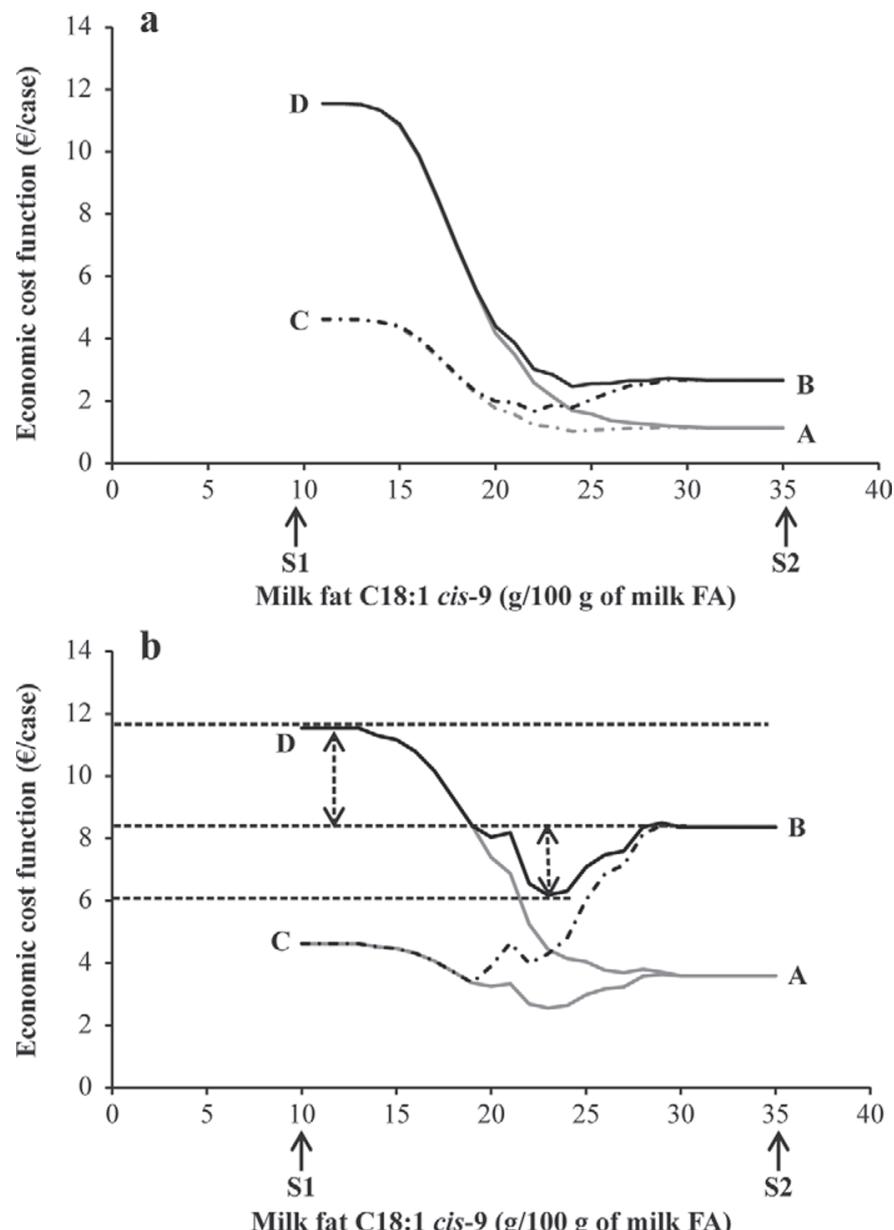

Figure 4. (a) Simulated economic cost of selectively treating cases showing $R \leq \theta$, based on the milk fat C18:1 cis-9 concentration $(R)$ with costs estimated for elevated blood plasma NEFA varying from $€ 15$ to 35 and daily propylene glycol (PEG) dosages varying from 200 to $500 \mathrm{~g} / \mathrm{d}$ applied over a period of $3 \mathrm{wk}$. To ensure clarity of the figures, only extreme simulations were presented (i.e., $\mathrm{A}=€ 15, \mathrm{~B}=$ $€ 35, C=200 \mathrm{~g}$, and D = 500 g). (b) Simulated economic cost of selectively treating cases showing $R \leq \theta$, based on the milk fat C18:1 cis-9 concentration $(R)$ monitored in wk 2 after parturition (early warning) with costs estimated for elevated blood plasma NEFA varying from $€ 15$ to 35 and daily PEG dosages varying from 200 to $500 \mathrm{~g} / \mathrm{d}$ applied over a period of $3 \mathrm{wk}$. To ensure clarity of the figures, only extreme simulations were presented (i.e., $\mathrm{A}=€ 15, \mathrm{~B}=€ 35, \mathrm{C}=200 \mathrm{~g}$, and $\mathrm{D}=500 \mathrm{~g})$.

\section{ACKNOWLEDGMENTS}

S. Jorjong acknowledges the support from the Royal Thai Government (Bangkok, Thailand) through a scholarship. The animal experiment was financed by the Dutch Dairy Board (Zoetermeer, the Netherlands), the Dutch Product Board Animal Feed (Zoetermeer, the Netherlands) and CRV (Arnhem, the Netherlands). Additionally, research was supported by an international coordinated action of the Fund for Scientific Research-Flanders (FWO; Brussels, Belgium).

\section{REFERENCES}

Ackman, R. G., and J. C. Sipos. 1964. Application of specific response factors in the gas chromatographic analysis of methyl esters of fatty acids with flame ionization detectors. J. Am. Oil Chem. Soc. $41: 377-380$

Cameron, R. E. B., P. B. Dyk, T. H. Herdt, J. B. Kaneene, R. Miller, and H. F. Bucholtz., J. S Liesman, M. J. V., and R. S. Emery. 1998. Dry cow diet, management, and energy balance as risk factors for displaced abomasum in high producing dairy herds. J. Dairy Sci. 81:132-139.

Chapinal, N., M. E. Carson, T. F. Duffield, M. Capel, S. Godden, M. Overton, J. E. Santos, and S. J. LeBlanc. 2011. The association of serum metabolites with clinical disease during the transition period. J. Dairy Sci. 94:4897-4903.

Chouinard, P. Y., V. Girard, and G. J. Brisson. 1997. Performance and profiles of milk fatty acids of cows fed full fat, heat-treated soybeans using various processing methods. J. Dairy Sci. 80:334-342.

CVB (Centraal Veevoederbureau). 2005. Veevoedertabel. Gegevens over chemische samenstelling, verteerbaarheid en voederwaarde van voedermiddelen. CVB, Lelystad, the Netherlands.

Formigoni, A., M. Cornil, A. Prandi, A. Mordenti, A. Rossi, D. Portetelle, and R. Renaville. 1996. Effect of propylene glycol supplementation around parturition on milk yield, reproduction performance and some hormonal and metabolic characteristics in dairy cows. J. Dairy Res. 63:11-24.

Garverick, H. A., M. N. Harris, R. Vogel-Bluel, J. D. Sampson, J. Bader, W. R. Lamberson, J. N. Spain, M. C. Lucy, and R. S. Youngquist. 2013. Concentration of nonesterified fatty acids and glucose in blood of periparturient dairy cows are indicative of pregnancy success at first insemination. J. Dairy Sci. 96:181-188.

Geishauser, T., K. Leslie, D. Kelton, and T. Duffield. 2001. Monitoring for subclinical ketosis in dairy herds. Comp. Cont. Educ. Pract. Vet. 23:S65-S71.

Grummer, R. R. 1993. Etiology of lipid-related metabolic disorders in periparturient dairy cows. J. Dairy Sci. 76:3882-3896.

Grummer, R. R., J. C. Winkler, S. J. Bertics, and V. A. Studer. 1994. Effect of propylene glycol dosage during feed restriction on metabolites in blood of prepartum Holstein heifers. J. Dairy Sci. $77: 3618-3623$.

Heuer, C., W. M. Van Straalen, Y. H. Schukken, A. Dirkzwager, and J. P. T. M. Noorhuizen. 2000. Prediction of energy balance in a high yielding dairy herd in early lactation: Model development and precision. Livest. Prod. Sci. 65:91-105.

Hostens, M., V. Fievez, J. L. M. R. Leroy, J. Van Ranst, B. Vlaeminck, and G. Opsomer. 2012. The fatty acid profile of subcutaneous and abdominal fat in dairy cows with left displacement of the abomasum. J. Dairy Sci. 95:3756-3765.

Johnson, R. B. 1954. The treatment of ketosis with glycerol and propylene glycol. Cornell Vet. 44:6-21.

LeBlanc, S. J., K. E. Leslie, and T. F. Duffield. 2005. Metabolic predictors of displaced abomasum in dairy cattle. J. Dairy Sci. $88: 159-170$.

Leroy, J. L. M. R., T. Vanholder, B. Mateusen, A. Christophe, G. Opsomer, A. de Kruif, G. Genicot, and A. Van Soom. 2005. Nonesterified fatty acids in follicular fluid of dairy cows and their effect on developmental capacity of bovine oocytes in vitro. Reproduction 130:485-495.

Lomander, H., J. Frössling, K. L. Ingvartsen, H. Gustafsson, and C. Svensson. 2012. Supplemental feeding with glycerol or propylene glycol of dairy cows in early lactation -Effects on metabolic status, body condition, and milk yield. J. Dairy Sci. 95:2397-2408.

Miyoshi, S., J. L. Pate, and D. L. Palmquist. 2001. Effect of propylene glycol drenching on energy balance, plasma glucose, plasma insulin, ovarian function and conception in dairy cows. Anim. Reprod. Sci. $68: 29-43$

Nielsen, N. I., and K. L. Ingvartsen. 2004. Propylene glycol for dairy cows. A review of the metabolism of propylene glycol and its effects on physiological parameters, feed intake, milk production and risk of ketosis. Anim. Feed Sci. Technol. 115:191-213. 
Ospina, P. A., D. V. Nydam, T. Stokol, and T. R. Overton. 2010a Evaluation of nonesterified fatty acids and $\beta$-hydroxybutyrate in transition dairy cattle in the northeastern United States: Critical thresholds for prediction of clinical diseases. J. Dairy Sci. 93:546-554.

Ospina, P. A., D. V. Nydam, T. Stokol, and T. R. Overton 2010b. Associations of elevated nonesterified fatty acids and $\beta$-hydroxybutyrate concentrations with early lactation reproductive performance and milk production in transition dairy cattle in the northeastern United States. J. Dairy Sci. 93:1596-1603.

Roberts, T., N. Chapinal, S. J. LeBlanc, D. F. Kelton, J. Dubuc, and T. F. Duffield. 2012. Metabolic parameters in transition cows as indicators for early-lactation culling risk. J. Dairy Sci. 95:30573063.

Rutten, M. J. M., H. Bovenhuis, K. A. Hettinga, H. J. F. van Valenberg, and J. A. M. van Arendonk. 2009. Predicting bovine milk fat composition using infrared spectroscopy based on milk samples collected in winter and summer. J. Dairy Sci. 92:6202-6209.

Seifi, H. A., S. J. LeBlanc, K. E. Leslie, and T. F. Duffield. 2011. Metabolic predictors of post-partum disease and culling risk in dairy cattle. Vet. J. 188:216-220.

Soyeurt, H., P. Dardenne, F. Dehareng, G. Lognay, D. Veselko, M. Marlier, C. Bertozzi, P. Mayeres, and N. Gengler. 2006. Estimating fatty acid concentration in cow milk using mid infrared spectrometry. J. Dairy Sci. 89:3690-3695.

Stefanov, I., V. Baeten, O. Abbas, E. Colman, B. Vlaeminck, B. De Baets, and V. Fievez. 2010. Analysis of milk odd- and branchedchain fatty acids using Fourier transform (FT)-Raman spectroscopy. J. Agric. Food Chem. 58:10804-10811.
Tamminga, S., W. M. Van Straalen, A. P. J. Subnel, R. G. M. Meijer, A. Steg, C. J. G. Wever, and M. C. Blok. 1994. The Dutch protein evaluation system: The DVE/OEB system. Livest. Prod. Sci. 40:139-155.

Townsend, J. 2011. Cowside tests for monitoring metabolic disease. Accessed Nov. 2013. http://tristatedairy.osu.edu/Proceedings $\% 20$ 2011/Townsend\%20paper.pdf.

van Dorland, H. A., S. Richter, I. Morel, M. G. Doherr, N. Castro, and R. M. Bruckmaier. 2009. Variation in hepatic regulation of metabolism during the dry period and in early lactation in dairy cows. J. Dairy Sci. 92:1924-1940.

Van Es, A. J. H. 1975. Feed evaluation for dairy cows. Livest. Prod. Sci. 4:95-107.

van Knegsel, A. T. M., G. Remmelink, S. Jorjong, V. Fievez, and B. Kemp. 2014. Effect of dry period length and dietary energy source on energy balance, milk yield and milk composition of dairy cows. J. Dairy Sci. 97:1499-1512.

van Vuuren, A. M., C. J. Van Der Koelen, H. Valk, and H. De Visser. 1993. Effects of partial replacement of ryegrass by low protein feeds on rumen fermentation and nitrogen loss by dairy cows. J. Dairy Sci. 76:2982-2993.

Vlaeminck, B., V. Fievez, A. R. J. Cabrita, A. J. M. Fonseca, and R J. Dewhurst. 2006. Factors affecting odd- and branched-chain fatty acids in milk: A review. Anim. Feed Sci. Technol. 131:389-417.

Wolff, R. L., C. C. Bayard, and R. J. Fabien. 1995. Evaluation of sequential methods for the determination of butterfat fatty acid composition with emphasis on trans-18:1 acids. Application to the study of seasonal variations in French butters. J. Am. Oil Chem. Soc. 72:1471-1483. 